\title{
Damage mechanics based predictions of creep crack growth in 316 stainless steel
}

\author{
C.J. Hyde, T.H. Hyde, W. Sun and A.A. Becker \\ Department of Mechanical, Materials and Manufacturing Engineering, University of Nottingham, \\ Nottingham, NG7 2RD, UK
}

\begin{abstract}
This paper describes a novel modelling process for creep crack growth prediction of a 316 stainless steel using continuum damage mechanics, in conjunction with finite element (FE) analysis. A damage material behaviour model, proposed by Liu and Murakami [1], was used which is believed to have advantages in modelling components with cracks. The methods used to obtain the material properties in the multiaxial form of the creep damage and creep strain equations are described, based on uniaxial creep and creep crack growth test data obtained at $600^{\circ} \mathrm{C}$. Most of the material constants were obtained from uniaxial creep test data. However, a novel procedure was developed to determine the tri-axial stress state parameter in the damage model by use of creep crack growth data obtained from testing of compact tension (CT) specimens. The full set of material properties derived were then used to model the creep crack growth for a set of thumbnail crack specimen creep tests which were also tested at $600^{\circ} \mathrm{C}$. Excellent predictions have been achieved when comparing the predicted surface profiles to those obtained from experiments. The results obtained clearly show the validity and capability of the continuum damage modelling approach, which has been established, in modelling the creep crack growth for components with complex initial crack shapes.
\end{abstract}

\section{Keywords}

Creep crack growth, Damage, 316 stainless steel, Liu and Murakami model, Finite Element Method.

\author{
Notation \\ $\dot{a} \quad$ crack growth rate \\ A constant in the Kachanov damage model (for $\dot{\varepsilon}_{e q}^{c}$ ) \\ B constant in the Kachanov damage model (for $\dot{\omega}$ ) \\ C constant in the Liu and Murakami damage model (for $\dot{\varepsilon}_{e q}^{c}$ ) \\ D constant in the Liu and Murakami damage model (for $\dot{\omega}$ ) \\ $C^{*} \quad$ creep contour integral \\ $m \quad$ constant in the Kachanov damage model (for $\dot{\boldsymbol{\varepsilon}}_{\text {eq }}^{c}$ )
}




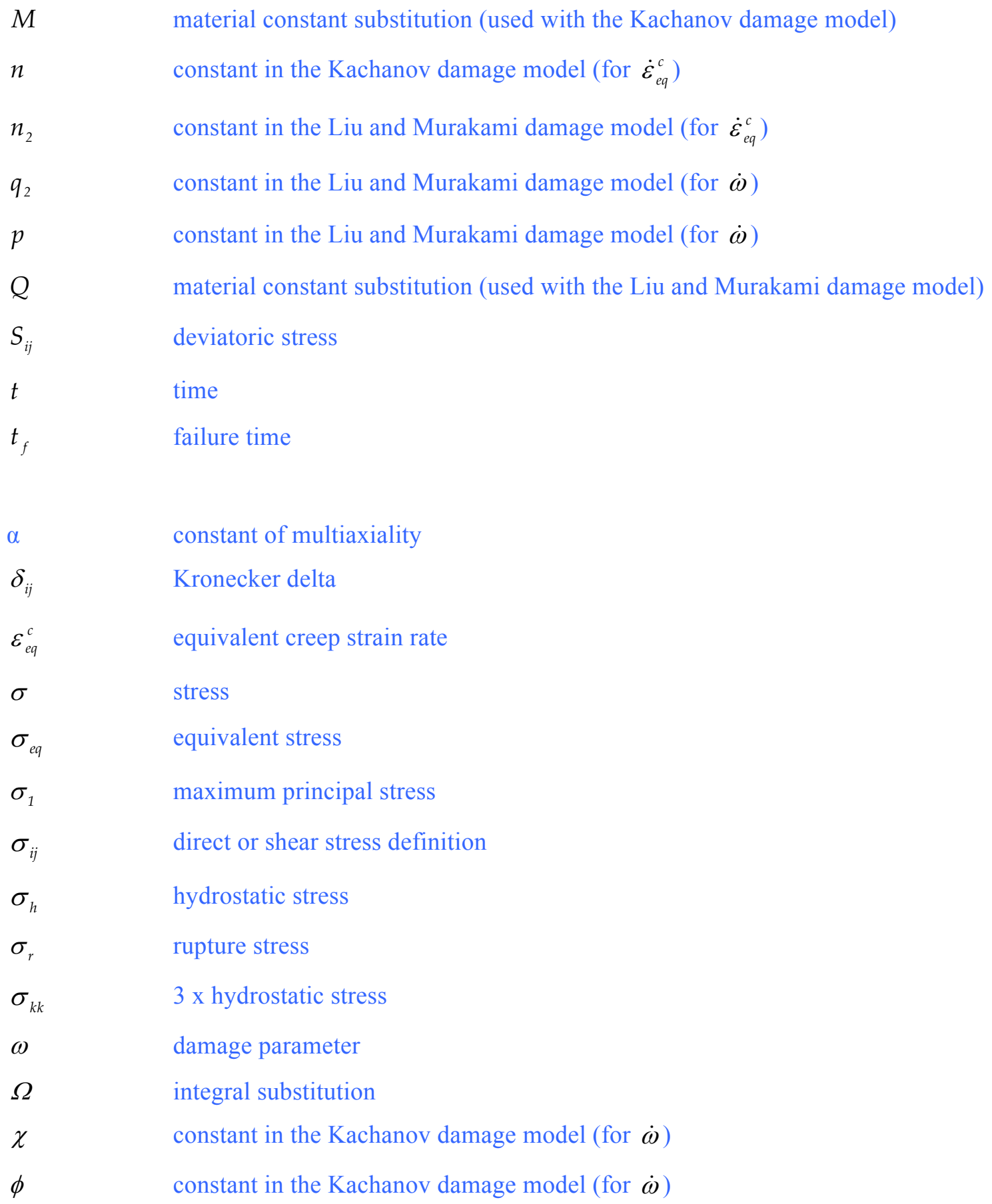

\section{Introduction}

Components in power plant, chemical plant, manufacturing processes, aeroengines, etc may operate at temperatures which are high enough for creep to occur [2]. Such components may contain cracks or must be assumed to contain cracks as part of design life or remaining life analyses which are required [3]. In order to perform these analyses a number of approaches have been used, based on, for example, a fracture mechanics approach using $\dot{a}-C^{*}$ relationships [4], or a damage mechanics approach $[5,6,1]$. This paper is related to the use of the damage mechanics approach. In particular the methods used to obtain the material constants in the multiaxial form of the creep 
damage and creep strain equations are described. Most of the constants are obtained by fitting to uniaxial creep data; this is a well established method [7]. However, in this paper, the determination of the multiaxial stress state parameter, $\alpha[8]$, is based on results from compact tension (CT) tests; this approach is novel and results in properties which are particularly suited for predicting creep crack growth in components, where the crack growth is defined by a damage parameter, $\omega$. When this damage parameter reaches a critical value ( 0.99 chosen for the presented work) the material is regarded as 'completely damaged' and hence a void or crack growth is assumed to be present. A previously used technique for obtaining the multiaxial stress state parameter, based on the notch strengthening which usually occurs in Bridgman notch [9] creep rupture tests, relative to corresponding uniaxial tests, does not closely represent the stress states and constraint which occur at crack tips. The validity of the method proposed in this paper is established by comparing finite element predictions of creep crack growth in thumbnail cracked specimens with experimental data [7] using the material constants obtained from uniaxial creep and CT creep test results.

The material chosen for the investigation is 316 stainless steel because of the ready availability of uniaxial creep, uniaxial creep rupture, compact tension creep crack growth and thumbnail creep crack growth data at a temperature of $600^{\circ} \mathrm{C}$. The particular form of damage equation chosen for the investigation is that proposed by Liu and Murakami [1]. By comparison with the more commonly used Kachanov damage equations [5], it was found that the Liu and Murakami equations do not cause the time steps in the finite element analyses to become impractically small and unlike the Kachanov equations, they produce results which are relatively insensitive to element size near the crack tip. These aspects are covered further in the paper.

\section{Experimental Testing}

Experimental testing was carried out using specimens of three geometries, namely, uniaxial, compact tension (CT) and thumbnail crack specimens. All tests presented were carried out at $600^{\circ} \mathrm{C}$ using specimens made from 316 stainless steel hot rolled plate. The chemical composition for this material is given in Table 1.

Table 1. Chemical composition of 316 stainless steel (\% weight).

\begin{tabular}{|c|c|c|c|c|c|c|c|c|}
\hline $\mathbf{C r}$ & $\mathbf{N i}$ & $\mathbf{M o}$ & $\mathbf{M n}$ & $\mathbf{S i}$ & $\mathbf{P}$ & $\mathbf{S}$ & $\mathbf{C}$ & $\mathbf{F e}$ \\
\hline 17.2 & 11.2 & 2.14 & 1.35 & 0.54 & 0.24 & 0.18 & 0.02 & Balance \\
\hline
\end{tabular}

\subsection{Uniaxial creep testing}

Uniaxial test data has been obtained using tensile creep specimens, the geometry of which is shown by Figure 1. The experiments were carried out under constant stress levels of $240 \mathrm{MPa}, 260 \mathrm{MPa}$, $280 \mathrm{MPa}$ and $300 \mathrm{MPa}$. The data from these tests is shown in Figure 2. 


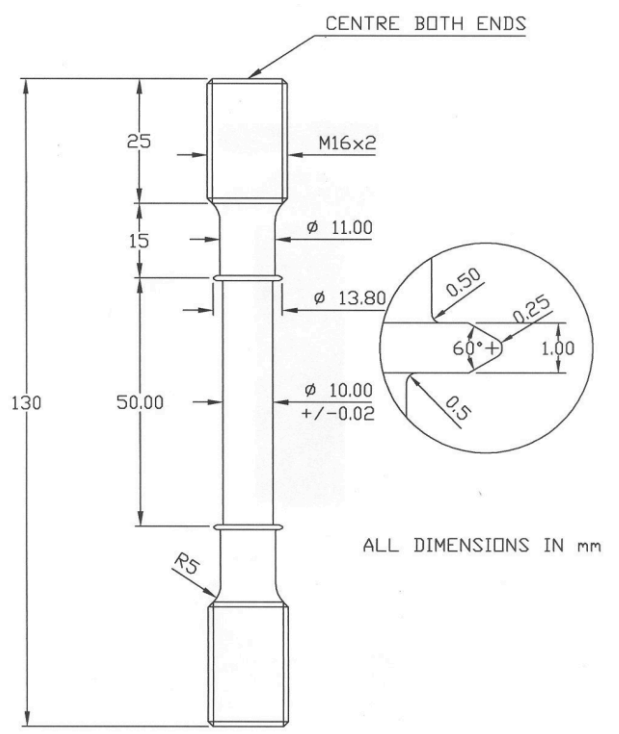

Figure 1. Uniaxial creep specimen geometry.

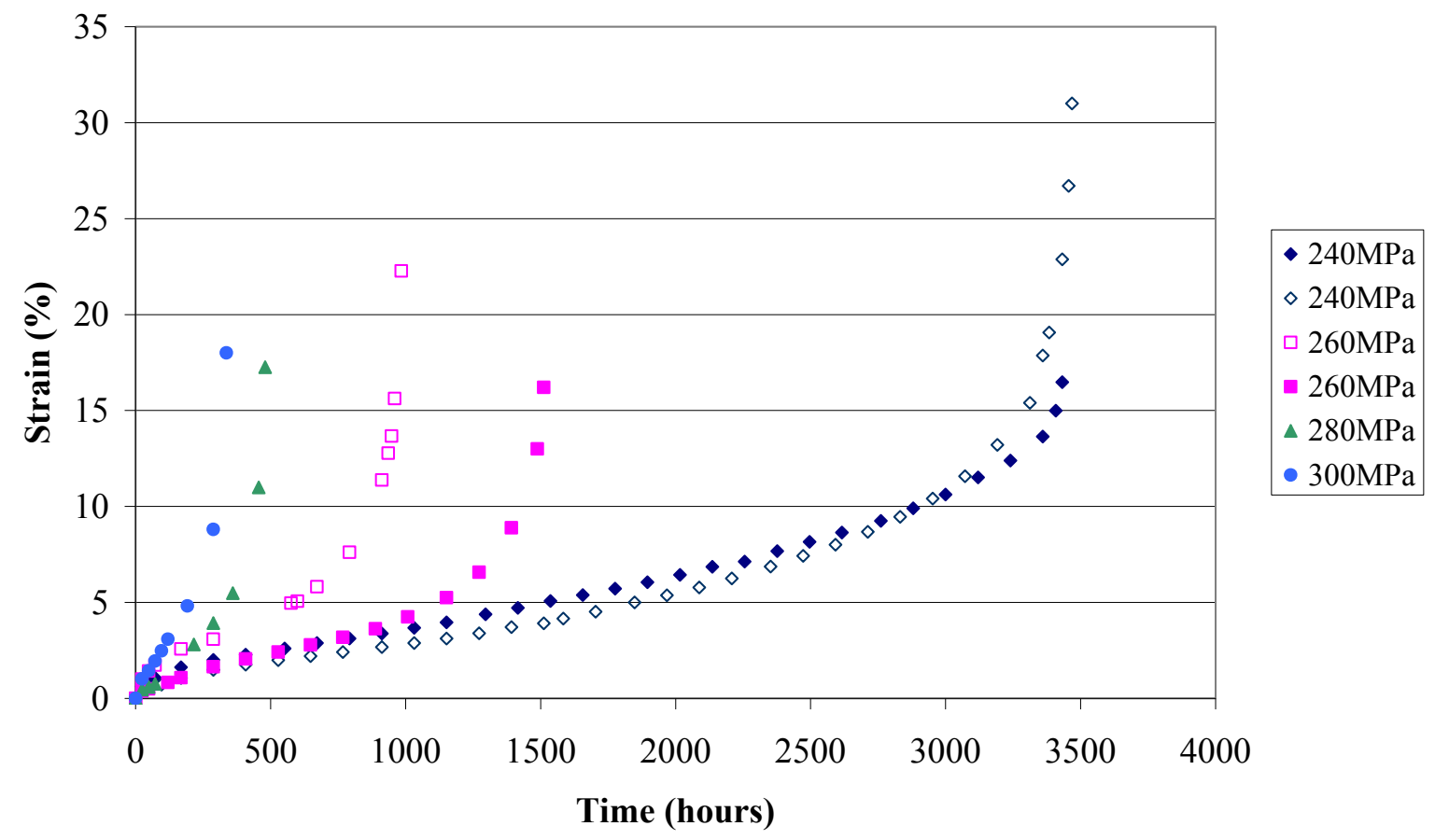

Figure 2. Uniaxial creep data for 316 stainless steel at $600^{\circ} \mathrm{C}$.

This data (Figure 2) has been used to obtain the uniaxial material constants in the creep damage model, as described in section 3.2.

\subsection{CT creep crack growth testing}

CT creep crack growth data has been obtained using specimens of the geometry shown in Figure 3. 

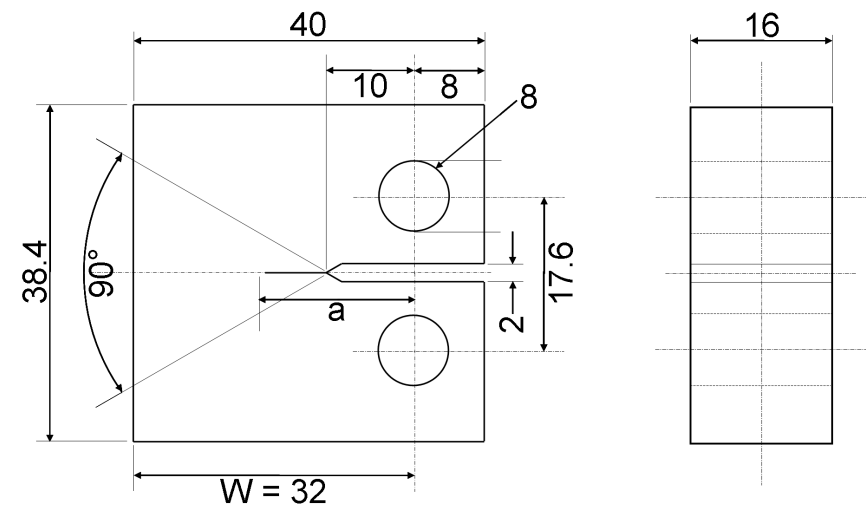

Figure 3. CT specimen geometry.

Three CT creep crack growth tests were carried out under constant loads of $6.977 \mathrm{kN}$ (specimen 2), $7.48 \mathrm{kN}$ (specimen 3 ) and $8.5 \mathrm{kN}$ (specimen 1) as shown by Table 2. Figure 4 shows photographs of the tested CT specimens where specimen 1 has been annotated in order to show the stages of crack growth for each test. Region 1 shows the starter notch, region 2 shows the initial (fatigue) crack, region 3 shows the creep crack, which gives the valuable part of the test data in the context of this work, region 4 shows further fatigue cracking in order to fracture the specimen for analysis and region 5 shows the end region where the specimen was torn open and fractured. The data obtained during region 3 is used to obtain the multiaxial stress state parameter, $\alpha$, as described in section 3.2.2 and is also compared to FE model predictions as shown in section 4.

Table 2. CT experimental test conditions.

\begin{tabular}{|c|c|c|c|}
\hline Test no. & Specimen no. & Load (kN) & Test duration (hours) \\
\hline 1 & 1 & 8.522 & 168 \\
\hline 2 & 2 & 6.977 & 892 \\
\hline 3 & 3 & 7.476 & 504 \\
\hline
\end{tabular}



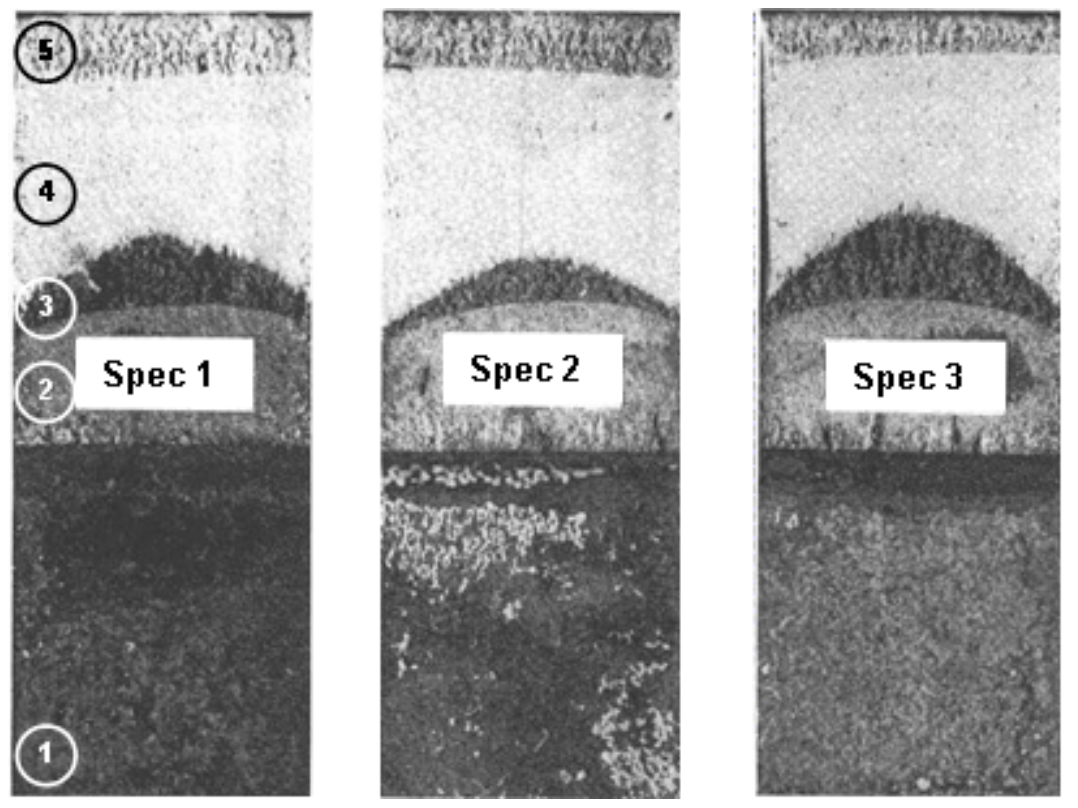

Figure 4. Photographs of creep cracked 316 stainless steel CT specimens.

\subsection{Thumbnail crack creep testing}

Thumbnail creep crack growth data has been obtained using specimens of the geometry shown in Figure 5.

a

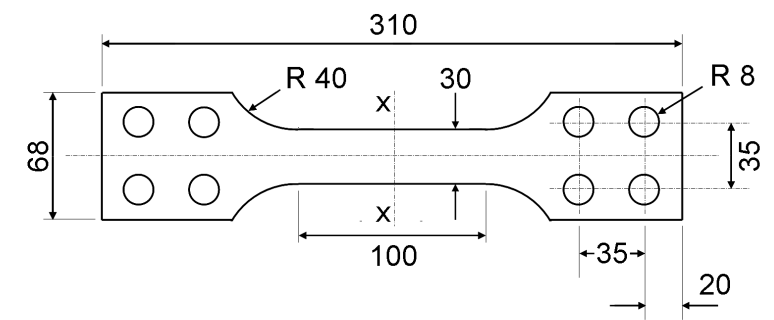

b

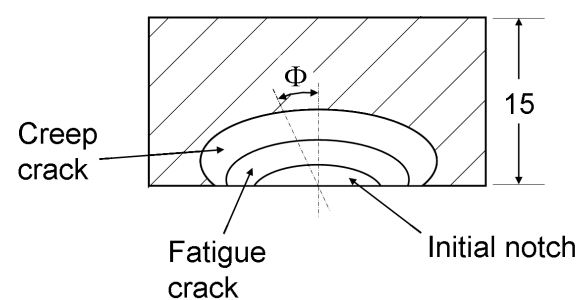

Figure 5. Thumbnail crack specimen (a) geometry, and (b) crack profile.

Five thumbnail creep crack growth tests were carried out under constant loads of $78.7 \mathrm{kN}$ (specimen 4), $90.7 \mathrm{kN}$ (specimen 6), $90.8 \mathrm{kN}$ (specimen 2), $91.7 \mathrm{kN}$ (specimen 7) and $102.3 \mathrm{kN}$ (specimen 8 ) as shown by Table 3. Figure 6 shows photographs of the tested thumbnail crack specimens where specimen 5 has been annotated in order to show the stages of crack growth for each test. Region 1 shows the starter notch, region 2 shows the initial (fatigue) crack, region 3 shows the creep crack, 
which again gives the valuable part of the test data in the context of this work, region 4 shows further fatigue cracking in order to fracture the specimen into two pieces and region 5 shows the end region where the specimen was torn open and fractured. The data obtained during region 3 is compared to FE model predictions as shown in section 3.2.2 and section 4.

Table 3. CT experimental test conditions.

\begin{tabular}{|c|c|c|c|}
\hline Test no. & Specimen no. & Load (kN) & Test duration (hours) \\
\hline 1 & 4 & 78.7 & 1176 \\
\hline 2 & 5 & 90.8 & 2760 \\
\hline 3 & 6 & 90.7 & 1200 \\
\hline 4 & 7 & 91.7 & 504 \\
\hline 5 & 8 & 102.3 & 504 \\
\hline
\end{tabular}
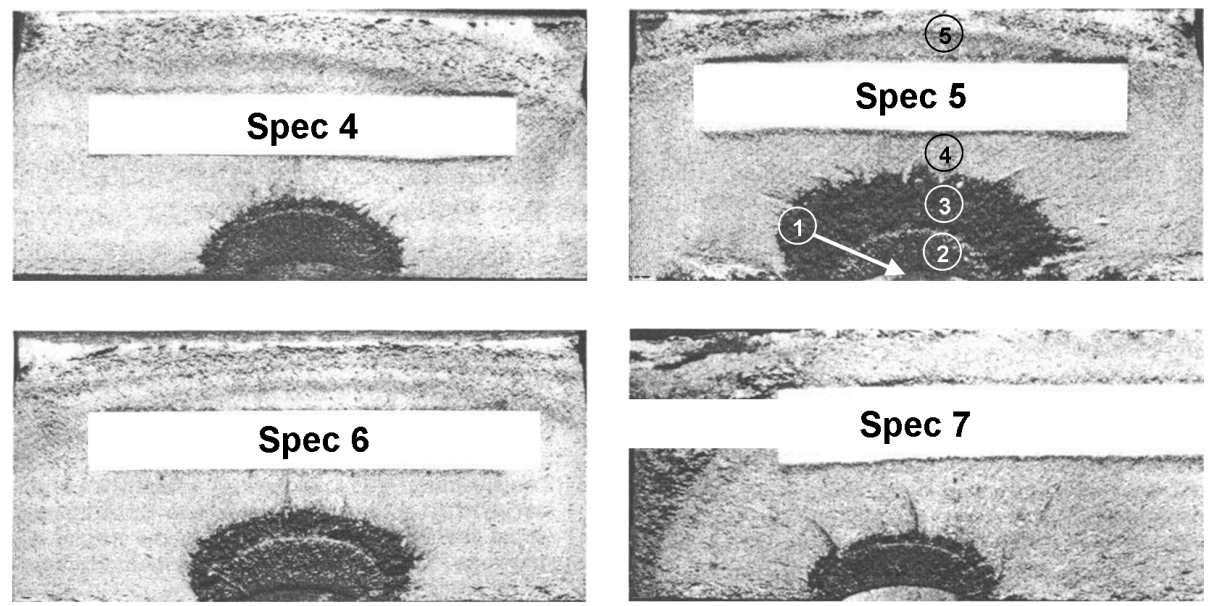

\section{Spec 7}
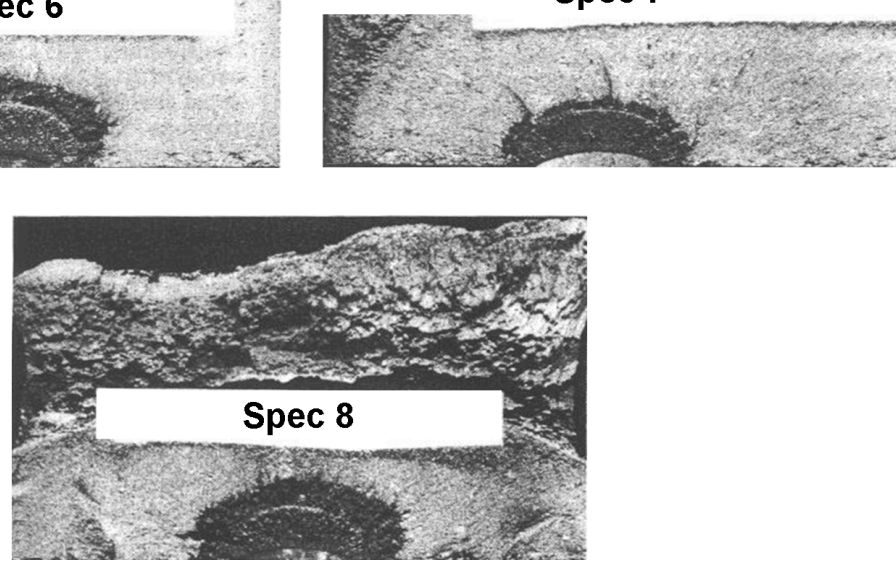

Figure 6. Photographs of creep cracked 316 stainless steel thumbnail crack specimens.

\section{Liu \& Murakami creep damage model}

\subsection{Definition of the material model}

The multiaxial form of the Liu and Murakami creep damage law is as follows: 


$$
\dot{\varepsilon}_{e q}^{c}=\frac{3}{2} C \sigma_{e q}^{n_{2}} \frac{S_{i j}}{\sigma_{e q}} \exp \left(\frac{2\left(n_{2}+1\right)}{\pi \sqrt{1+3 / n_{2}}} \cdot\left(\frac{\sigma_{1}}{\sigma_{e q}}\right) \cdot \omega^{3 / 2}\right)
$$

where $\mathrm{C}$ and $\mathrm{n}_{2}$ are material constants. $\varepsilon_{e q}^{c}$ and $\sigma_{e q}$ are the equivalent strain and equivalent stress, respectively, and $\sigma_{1}$ is the maximum principle stress. $S_{i j}$ is the deviatoric stress, i.e.:

$$
S_{i j}=\sigma_{i j}-\frac{1}{3} \delta_{i j} \sigma_{k k}
$$

in which $\delta_{i j}$ is the Kronecker delta and is defined as:

$$
\delta_{i j}= \begin{cases}1 & i=j \\ 0 & i \neq j\end{cases}
$$

and

$$
\sigma_{k k}=3 \sigma_{h}
$$

where $\sigma_{h}$ is the hydrostatic stress, defined as:

i.e.

$$
\sigma_{h}=\frac{\sigma_{11}+\sigma_{22}+\sigma_{33}}{3}
$$

$\omega$ is the damage variable, and is given as:

$$
\dot{\omega}=D \frac{\left(1-e^{-q_{2}}\right)}{q_{2}} \sigma_{r}^{p} e^{q_{2} \omega}
$$

When this value reaches a critical value ( 0.99 within the present work), crack growth is assumed to have occurred into the regions where this has happened. $\mathrm{D}, \mathrm{q}_{2}$ and $\mathrm{p}$ are material constants. $\sigma_{r}$ is the rupture stress defined as:

$$
\sigma_{r}=\alpha \sigma_{1}+(1-\alpha) \sigma_{e q}
$$

where $\alpha$ is a material constant which describes the effect of multi-axial stress states.

Under the uniaxial condition:

$$
\sigma_{1}=\sigma_{e q}=\sigma
$$

and $\sigma_{11}$ can be substituted for $\sigma_{1}$.

Therefore, substituting equation (7) into equation (6) gives:

$$
\sigma_{r}=\sigma_{e q}
$$

and therefore, from equation (7):

$$
\sigma_{1}=\sigma_{e q}=\sigma_{r}=\sigma
$$

Hence, for the uniaxial condition, it is not possible to determine the material constant, $\alpha$. Also, for the uniaxial condition (the 11-direction), equation (2) can be simplified to: 


$$
S_{11}=\sigma-\frac{1}{3} \sigma=\frac{2}{3} \sigma
$$

as $\sigma_{22}$ and $\sigma_{33}$ are both equal to zero and $\sigma_{11}=\sigma_{1}=\sigma_{e q}=\sigma$ under the uniaxial condition.

Therefore, substituting equations (9) and (7) into equation (1) gives:

$$
\dot{\varepsilon}^{c}=C \sigma^{n_{2}} \exp \left(\frac{2\left(n_{2}+1\right)}{\pi \sqrt{1+3 / n_{2}}} \cdot \omega^{3 / 2}\right)
$$

Also, for the uniaxial condition, equation (8) can be substituted into equation (5) to give:

$$
\dot{\omega}=D \frac{\left(1-e^{-q_{2}}\right)}{q_{2}} \sigma^{p} e^{q_{2} \omega}
$$

\subsection{Determination of the material constants}

From equations (1), (5) and (6), it can be seen that the constants which are required to be obtained are $\mathrm{C}, \mathrm{n}_{2}, \mathrm{D}, \mathrm{q}_{2}, \mathrm{p}$ and $\alpha$. Methodologies for obtaining these constants are described as follows:

\subsubsection{Uniaxial material constants $\left(C, n_{2}, D, q_{2}\right.$ and $\left.p\right)$}

(a) $\mathrm{C}$ and $\mathbf{n}_{2}$

During the initial stages of the creep of a material, $\omega \approx 0$ and hence: $\exp \left(\frac{2\left(n_{2}+1\right)}{\pi \sqrt{1+3 / n_{2}}} \cdot \omega^{3 / 2}\right) \approx \exp (0)=1$. Therefore equation (10) can be simplified to the following:

$$
\dot{\varepsilon}^{c}=C \sigma^{n_{2}}
$$

Taking logs of both sides of equation (12) gives,

$$
\log \left(\dot{\varepsilon}^{c}\right)=n_{2} \log (\sigma)+\log (C)
$$

Therefore, using experimental uniaxial creep data to plot $\log \left(\dot{\varepsilon}^{c}\right)$ vs. $\log (\sigma)$ and fitting a straight line of best fit through this data allows the identification of $n_{2}$ from the gradient and $C$ from the y-axis intercept. An example of this plot is shown in Figure 7, for 316 stainless steel, at $600^{\circ} \mathrm{C}$. The $\mathrm{C}$ and $\mathrm{n}_{2}$ values determined for the 316 stainless steel, at $600^{\circ} \mathrm{C}$, are included in Table 4 . 


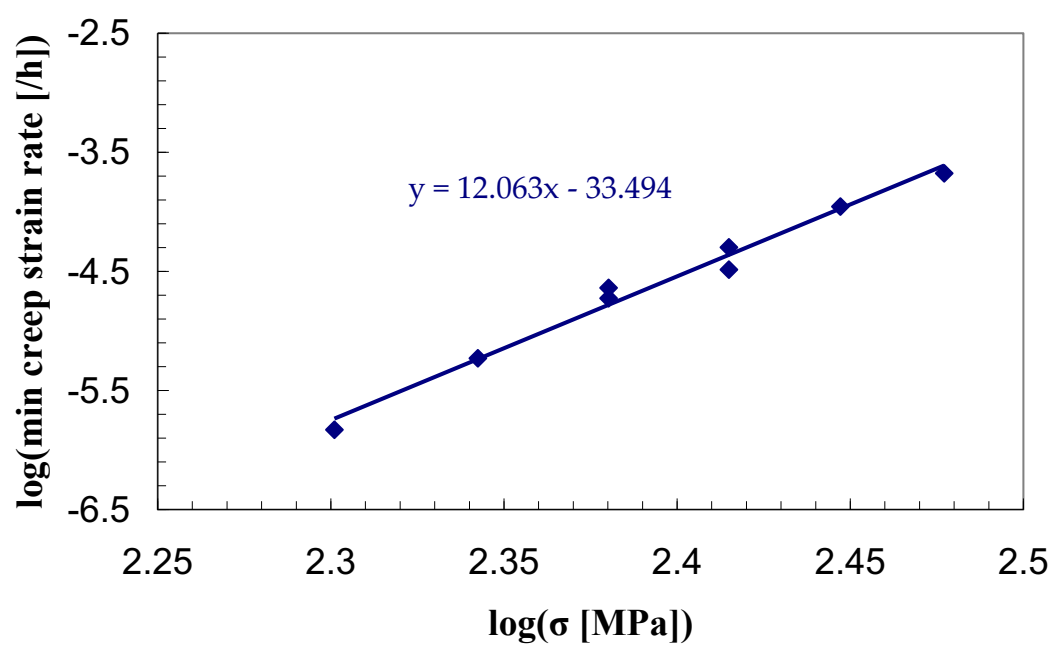

Figure 7. Linear fit to creep strain rate vs. $\sigma$ on a log-log scale.

\section{(b) D and $p$}

Equation (5) can be written as follows:

$$
\frac{d \omega}{d t}=D \frac{\left(1-e^{-q_{2}}\right)}{q_{2}} \sigma^{p} e^{q_{2} \omega}
$$

Separating the variables for integration gives:

$$
\frac{d \omega}{e^{q_{2} \omega}}=D \frac{\left(1-e^{-q_{2}}\right)}{q_{2}} \sigma^{p} d t
$$

Since the right hand side of equation (13) is made up of entirely constants, equation (13) can be rewritten as:

$$
\frac{d \omega}{e^{q_{2} \omega}}=Q d t
$$

where

$$
Q=D \frac{\left(1-e^{-q_{2}}\right)}{q_{2}} \sigma^{p}=\text { constant }
$$

Integrating equation (14) between the limits of 0 and 1 , for $\omega$, and 0 and $t_{f}$, for $t$ gives:

$$
\int_{0}^{1} e^{-q_{2} \omega} d \omega=Q \int_{0}^{t_{f}} d t
$$

Equation (16) can be further simplified using the substitution:

$$
-q_{2} \omega=\Omega
$$

and therefore

$$
-q_{2} d \omega=d \Omega
$$

Therefore, equation (16) becomes:

$$
\int_{0}^{-q_{2}} \frac{e^{\Omega}}{-q_{2}} d \Omega=Q \int_{0}^{t_{f}} d t
$$

Note that the damage integration limits have also changed as a result of the substitution shown by equations (17) and (18). Equation (19) can be solved to give: 


$$
\frac{1-e^{-q_{2}}}{q_{2}}=Q t_{f}
$$

Substituting equation (15) into equation (20) gives the following:

$$
t_{f}=\frac{\sigma^{-p}}{D}
$$

Taking logs of both sides of equation (21) gives:

$$
\log \left(t_{f}\right)=-p \log (\sigma)+\log \left(\frac{1}{D}\right)
$$

Therefore, plotting $\log \left(t_{f}\right)$ vs. $\log (\sigma)$ using data obtained from uniaxial (as for this condition, $\left.\log \left(\sigma_{r}\right)=\log (\sigma)\right)$ experiments, allows the identification of both $p$, from the gradient of the straight line of best fit and $D$, from the y-intercept. Figure 8 shows an example of this plot for uniaxial, 316 stainless steel data at $600^{\circ} \mathrm{C}$. The $\mathrm{D}$ and $\mathrm{p}$ values obtained for the 316 stainless steel, at $600^{\circ} \mathrm{C}$, are included in Table 4.

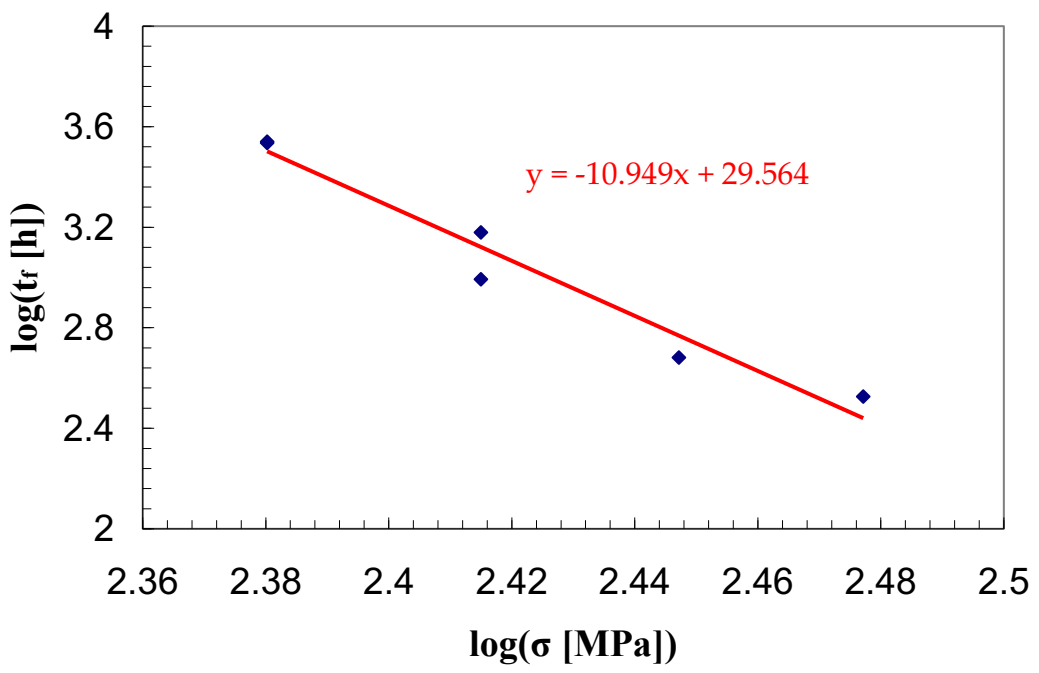

Figure 8. Linear fit to $\log \left(t_{f}\right)$ vs. $\log (\sigma)$.

(c) $q_{2}$

At this stage, all of the constants required in the uniaxial version of the Liu and Murakami model are known, except the $q_{2}$ value. A curve fitting process is used on the $\varepsilon^{c}$ vs. time data in order to determine the value of $q_{2}$ which is the optimum fit at all stress levels.

In order to plot $\varepsilon^{c}$ vs. time using the model, $\varepsilon^{c}$ must first be found as a function of $t$. As equation (10) shows, $\dot{\varepsilon}^{c}$ is a function of $\omega$ as well as $t . \omega$ is also a function of $t$, as shown by equation (11). Therefore, this expression for $\omega$ as a function of $t$ must first be found, which can then be substituted into equation (10) to give an expression for $\varepsilon^{c}$ as a function of $t$. Integrating equation (14), between the limits of 0 and $\omega$, for $\omega$, and 0 and $t$, for $t$, leads to an expression for $\omega$ as a function of $t$, i.e., 


$$
\int_{0}^{\omega} \frac{d \omega}{e^{q_{2} \omega}}=Q \int_{0}^{t} d t
$$

Again, using the substitution shown by equations (17) and (18) gives:

$$
\int_{0}^{-q_{2} \omega} \frac{e^{\Omega}}{-q_{2}} d \Omega=Q \int_{0}^{t} d t
$$

Equation (24) can be solved and re-arranged for $\omega$ to give:

$$
\omega=-\frac{\ln \left(1-Q q_{2} t\right)}{q_{2}}
$$

Substituting equation (15) into equation (25) gives:

$$
\omega=-\frac{\ln \left(1-D\left(1-e^{-q_{2}}\right) \sigma^{p} t\right)}{q_{2}}
$$

This is the expression for $\omega$ (as a function of $t$ ) which is needed in order to obtain an expression for $\varepsilon^{c}$ as a function of $t$.

Equation (26) is substituted into equation (10) to give:

$$
\dot{\varepsilon}^{c}=C \sigma^{n_{2}} \exp \left(\frac{2\left(n_{2}+1\right)}{\pi \sqrt{1+3 / n_{2}}} \cdot\left(-\frac{\ln \left(1-D\left(1-e^{-q_{2}}\right) \sigma^{p} t\right)}{q_{2}}\right)^{3 / 2}\right)
$$

Equation (27) cannot be readily solved to produce a closed form solution for $\varepsilon^{c}$ as a function of time. However, a time marching procedure can be used to obtain the variation of $\varepsilon^{c}$ with time. This time marching procedure is carried out by calculating $\dot{\varepsilon}^{c}$ for many small time steps, up to the failure time, and multiplying each of these values by the small time interval in order to give the creep strain increment for that time interval, as shown by the following equation:

$$
\Delta \varepsilon_{i}^{c}=\dot{\varepsilon}_{i}^{c} \times \Delta t
$$

where $i$ denotes the current time step.

These creep strain increments are then accumulated in order to give the total value of creep strain at the end of each time step, i.e.

$$
\varepsilon_{i}^{c}=\varepsilon_{i-1}^{c}+\Delta \varepsilon_{i}^{c}
$$

Stress, $\sigma$, is assumed to be constant for every time increment. Curves of $\varepsilon^{c}$ vs. $t$ can then be plotted for each stress value. $q_{2}$ can then be varied in order to optimise the general fit (for all $\sigma$ values) of the model to the experimental data. An example of this plot using uniaxial creep data for 316 stainless steel, at $600^{\circ} \mathrm{C}$, is shown by Figure 9 . The $\mathrm{q}_{2}$ value obtained for the 316 stainless steel, at $600^{\circ} \mathrm{C}$, is included in Table 4. 


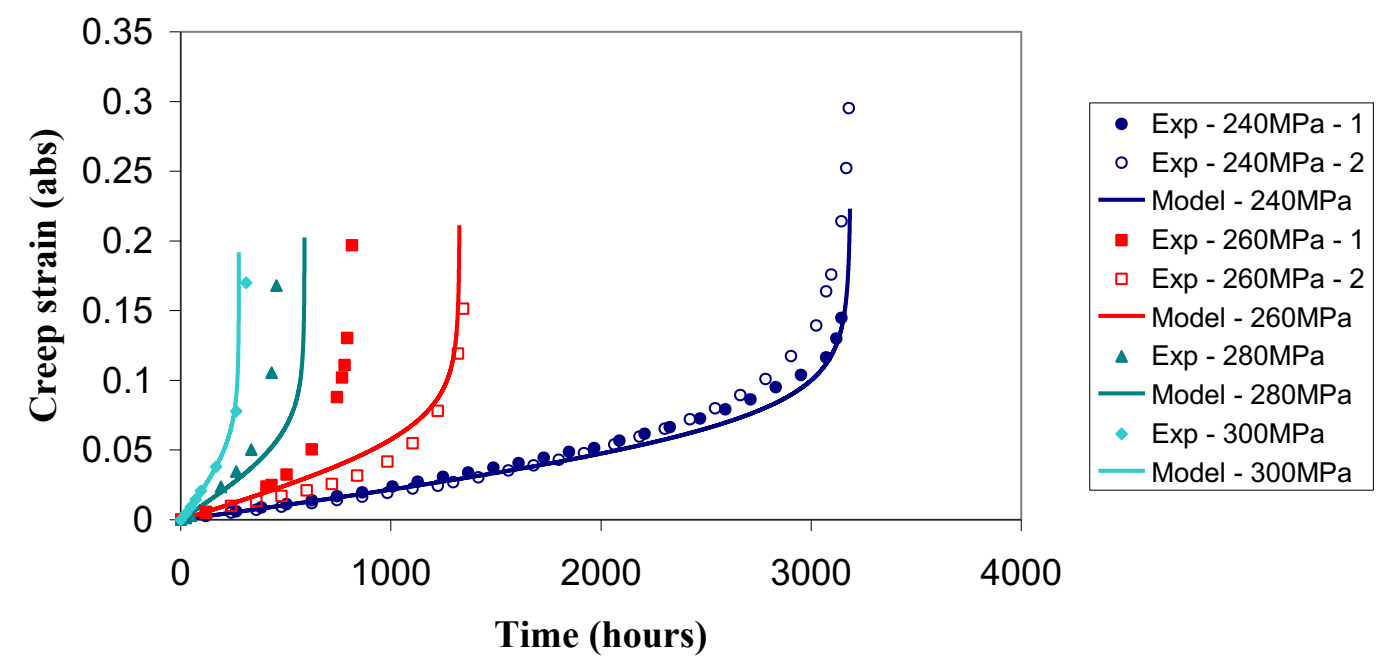

Figure 9. Comparison of the Liu and Murakami creep damage model to uniaxial, experimental creep data.

\subsubsection{Multiaxiality parameter, $\alpha$}

Equation (6) is used for the rupture stress, $\sigma_{\mathrm{r}}$, within the model to include the multiaxial stress effect. Within this equation is the material constant, $\alpha$, which is not required for the uniaxial condition. However, if a multiaxial stress condition exists, the $\alpha$ value is required:

Equation (5) can be re-written as:

$$
\frac{d \omega}{d t}=D \frac{\left(1-e^{-q_{2}}\right)}{q_{2}} \sigma_{r}^{p} e^{q_{2} \omega}
$$

Following the process described by equations (13) to (21), with $\sigma$ replaced by $\sigma_{r}$ gives:

$$
t_{f}=\frac{\sigma_{r}^{-p}}{D}
$$

Therefore, substituting equation (6) into equation (28) gives:

$$
t_{f}=\frac{1}{D\left(\alpha \sigma_{1}+(1-\alpha) \sigma_{e q}\right)^{p}}
$$

Two basic approaches have been used in order to determine the $\alpha$-value for a material. The most straightforward method involves performing tests on specimens with specific biaxial stress states [10] and to obtain the $\alpha$ value which fits equation (29) to the experimental data. However, tests of this type are complicated and require careful specimen design and complicated test facilities [11]. For this reason an alternative approach based on the data obtained from notched bar creep test specimens has been more widely used to obtain the $\alpha$-values.

Notched bars are tested under steady load conditions and the failure times obtained. A series of finite element (FE) modelling of the experimental tests are then carried out using the material properties 
$\left(\mathrm{C}, \mathrm{n}_{2}, \mathrm{D}, \mathrm{p}\right.$, and $\left.\mathrm{q}_{2}\right)$ obtained from the corresponding uniaxial test data, together with a different $\alpha$ value for each calculation. The $\alpha$-value which results in the same failure time as that of the experimental notched bar test is taken to be the $\alpha$-value in the expression for rupture stress (equation (6)). The average $\alpha$-value for a range of load levels applied in the experiments gives a reasonable estimate for the "actual" $\alpha$-value. The process is capable of giving $\alpha$-values which can be used with confidence when the triaxial stress state in the notch region, where final fracture occurs, is similar to that in the components for which damage zones and failure times are to be determined. However, crack tips have particularly severe multiaxial stress states and magnitudes and hence the damage regions tend to grow in a "crack-like" manner. Therefore, for these situations, it would be advantageous if the $\alpha$-value was obtained from tests on cracked components. This novel approach has been adopted in this paper. A series of FE calculations, to predict the creep crack growth in the experimental CT specimens, as shown in Figure 4, were carried out for the experimental test durations, using the same load levels.

Different $\alpha$-values were used for each calculation performed for each test. A typical threedimensional FE mesh and 0.99 damage (crack) zone for this CT specimen geometry is shown in Figure 10, where due to two axes of symmetry in a CT specimen, only one quarter of the specimen has been modelled, with the appropriate boundary conditions applied. The $\alpha$-value which gave the best overall fit to all of the experimental creep crack growth test data was found to be 0.48 . It is worth noting that the accurate determination of the $\alpha$-value is crucial in the accuracy of the damage predictions, therefore, throughout this process, care must be taken in order to ensure that the optimum $\alpha$-value is determined. The comparisons of the experimental and FE creep crack growths for the three CT specimens are shown in Figure 11, from which it can be seen that the crack front shapes, as well as the extents of creep crack growth were accurately predicted with $\alpha=0.48$. This $\alpha$-value has been used to predict the crack growth obtained for the thumbnail crack specimens, these predictions are compared with the experimental data in section 4. Further details of the FE modelling of the CT specimens and calculation of the optimum $\alpha$-value are given in Appendix 2. 


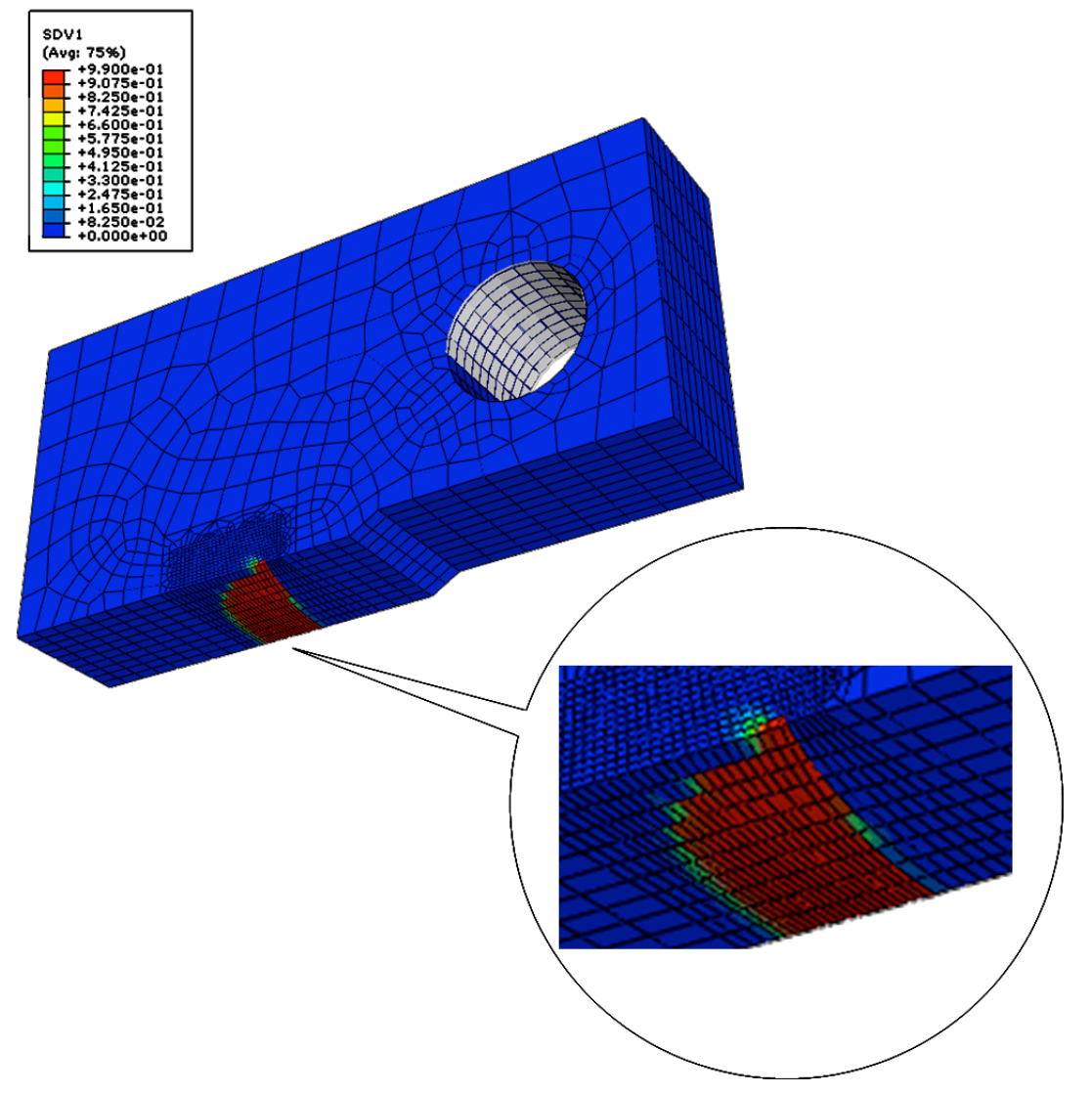

Figure 10. 3D CT specimen FE mesh.
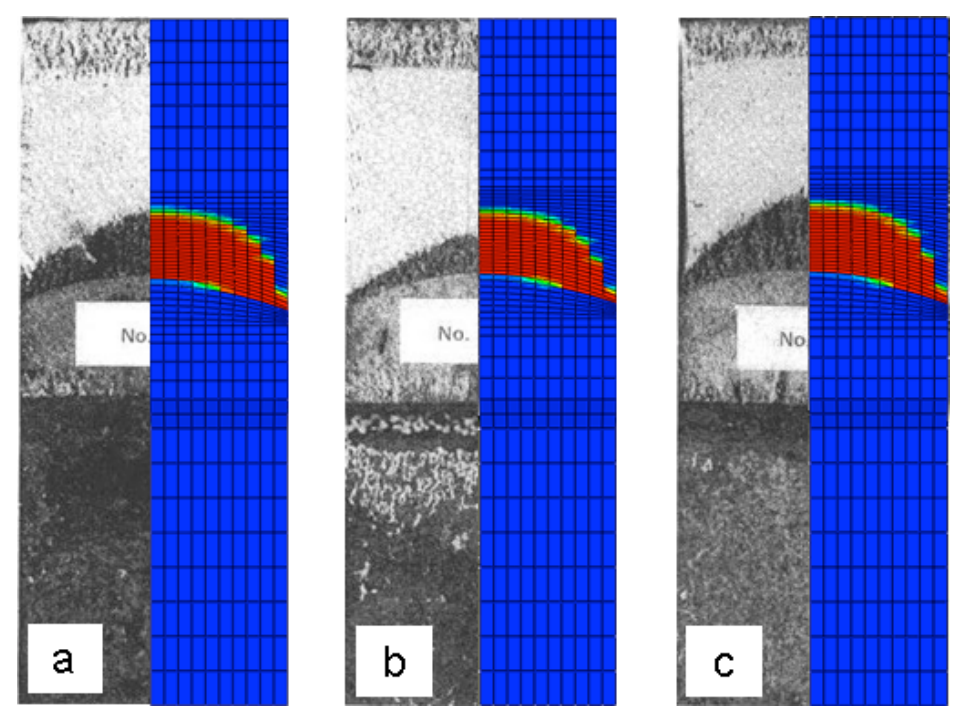

Figure 11. Tested specimen photo to FE damage contour comparisons

(a) Specimen 1 (b) Specimen 2 (c) Specimen 3.

Table 4. Liu and Murakami creep damage model material constants for 316 stainless steel at $600^{\circ} \mathrm{C}$.

\begin{tabular}{|c|c|c|c|c|c|}
\hline $\mathbf{C}$ & $\mathbf{n}_{\mathbf{2}}$ & $\mathbf{D}$ & $\mathbf{p}$ & $\mathbf{q}_{\mathbf{2}}$ & $\boldsymbol{\alpha}$ \\
\hline $1.47 \mathrm{e}-29$ & 10.147 & $2.73 \mathrm{e}-30$ & 10.949 & 6.35 & 0.47845 \\
\hline
\end{tabular}




\subsection{Advantage of the Lui \& Murakami model}

The Lui \& Murakami model has been favoured over the more widely used Kachanov model (the Kachanov model is briefly described in Appendix 1) for the following reason. Figure 12 shows uniaxial plots of creep strain versus time for 316 stainless steel at $600^{\circ} \mathrm{C}$ under a constant stress of $240 \mathrm{MPa}$ for both models. It can be seen that the curves from both of the models correspond very well.

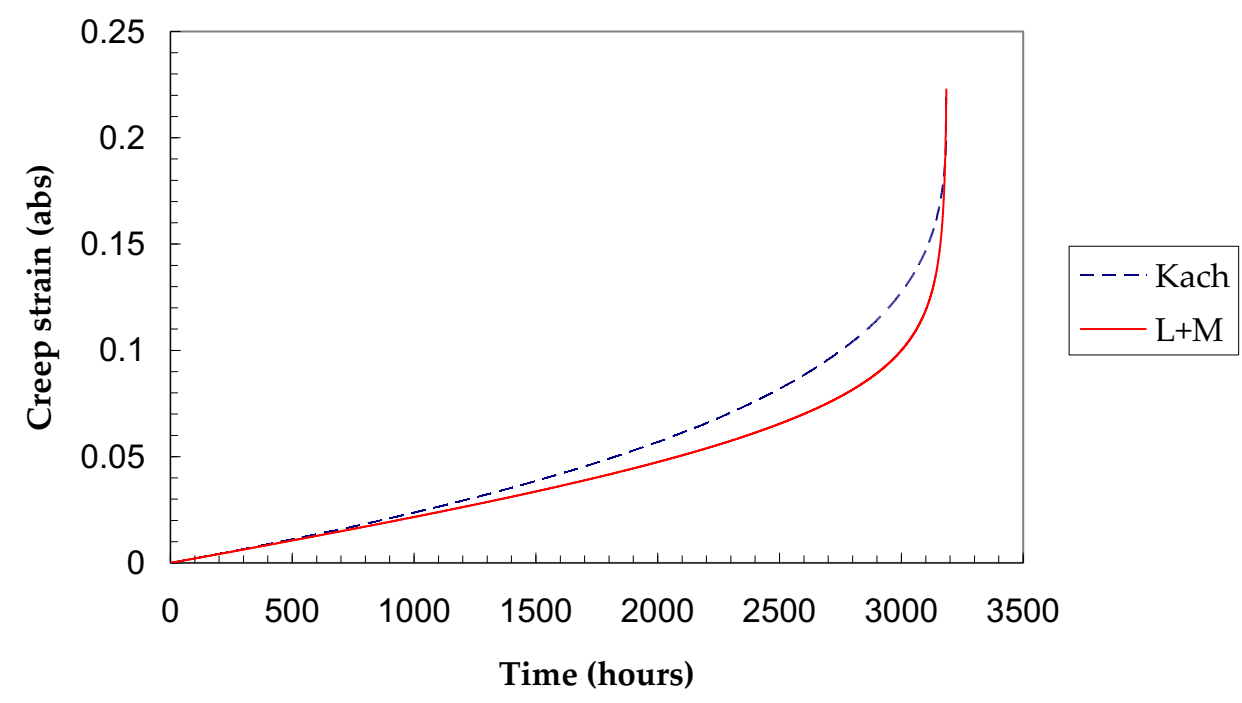

Figure 12. Comparison of uniaxial creep curves from the Lui \& Murakami and Kachanov models.

However, comparing plots of damage versus time, it can be seen that the damage rate obtained from the Kachanov model rapidly approaches infinity at times close to the failure time, as shown by the gradient of the dashed curve in Figure 13. This causes problems when running FE analyses, because the time step is continually reduced in order to obtain converged solutions and the calculation run time becomes impractically large. In the Lui and Murakami model, however, although the damage rate necessarily becomes large, it maintains a manageably low gradient (at high times) up to a damage value of 1, allowing analyses to be performed with more practical time steps and therefore relatively low calculation times. 


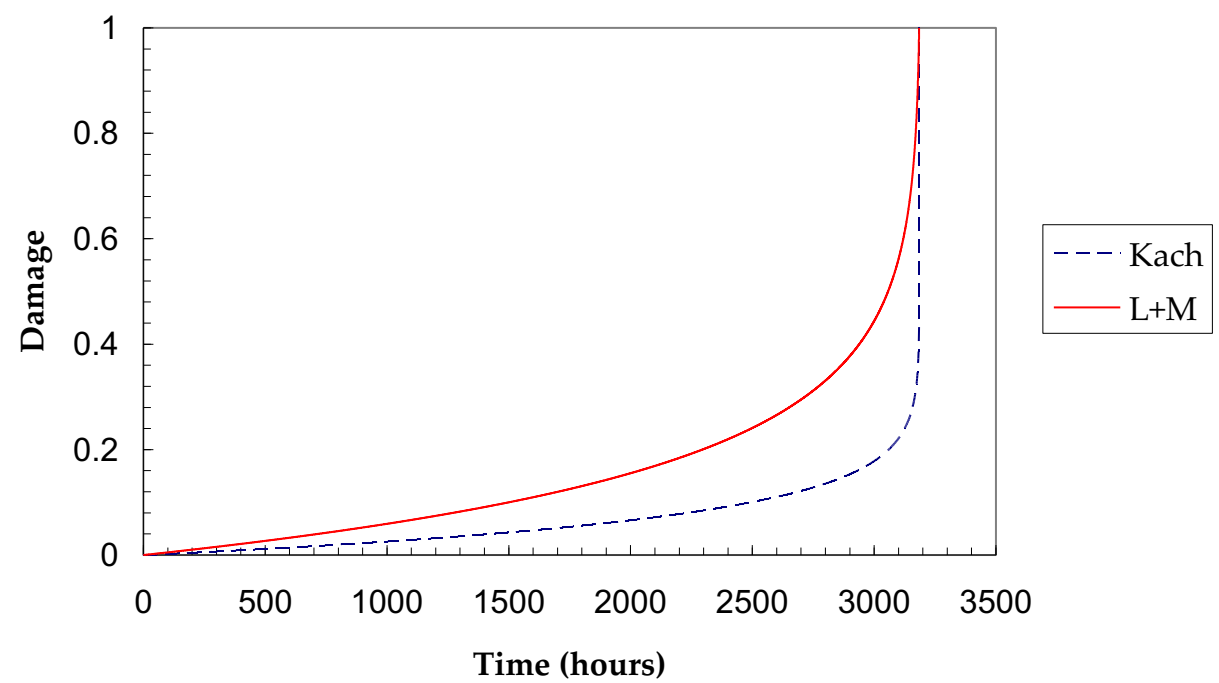

Figure 13. Comparison of uniaxial damage curves from the Lui \& Murakami and Kachanov models.

\section{Predictive capability of the model}

As the multiaxial constant, $\alpha$, was determined using the CT crack growth data, it is to some extent not surprising that the FE crack growth predictions correspond well to this experimental data, with all of the other material constants having been determined using data from uniaxial creep data. However, similar simulations have been performed for thumbnail crack geometries based on the same constants and can therefore be considered as 'pure prediction'. Figure 14 shows an example of the 3dimensional mesh (and 0.99 damage (crack) zone) used for the thumbnail crack growth simulations. As with the CT specimens, due to two axes of symmetry in a thumbnail crack specimen, only one quarter of the specimen has been modelled, with the appropriate boundary conditions applied. 


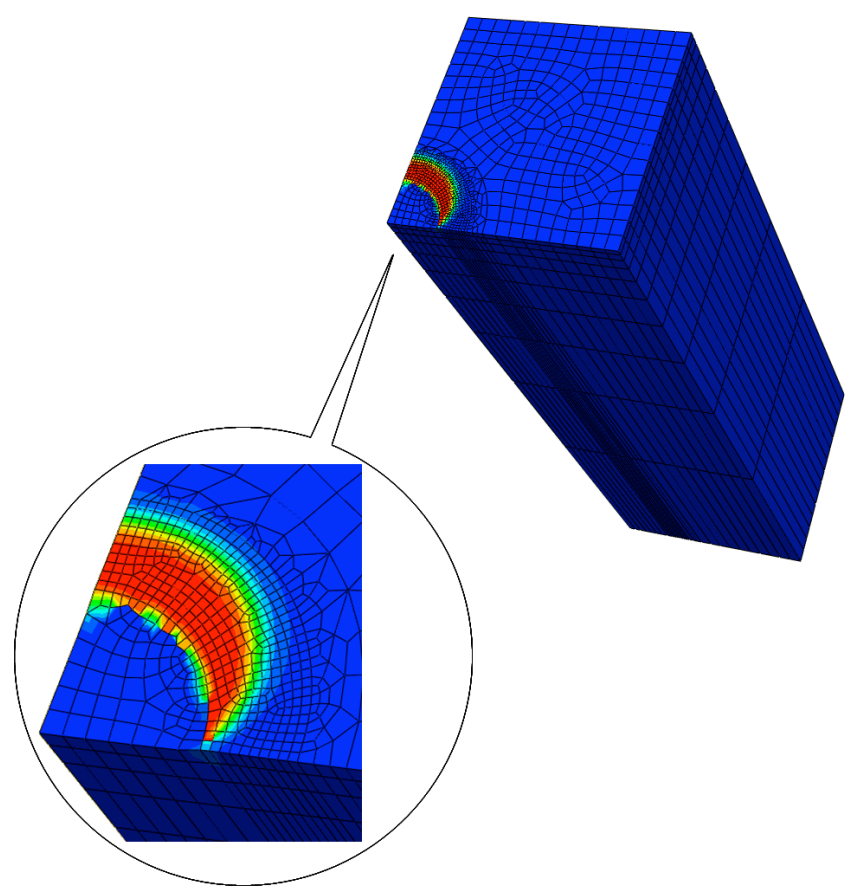

Figure 14. 3D thumbnail crack specimen FE mesh.

The comparisons of the experimental and FE creep crack growths for the five thumbnail specimens are shown in Figure 15, from which it can be seen that similarly to the CT predictions, the crack front shapes, as well as the extents of creep crack growth were accurately predicted with $\alpha=0.48$.
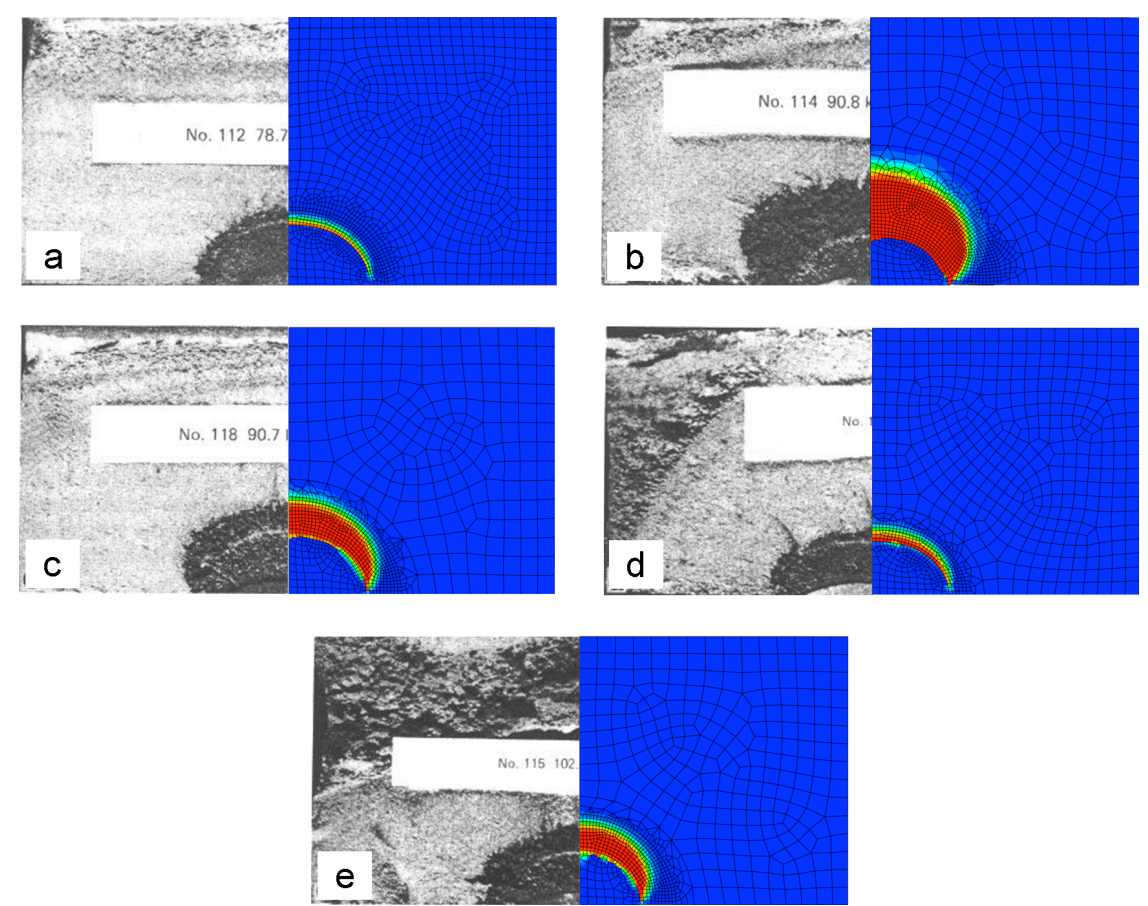

Figure 15. Tested specimen photo to FE damage contour comparisons

(a) Specimen 4 (b) Specimen 5 (c) Specimen 6 (d) Specimen 7 (e) Specimen 8. 


\subsubsection{Mesh sensitivity}

The sensitivity of the thumbnail crack growth simulations to the mesh used has been investigated by consideration of the test conditions used for specimen 6 (part (c) in Figure 15). Figure 16 shows the four meshes, (a), (b), (c) and (d) used in this investigation, where each mesh is finer than the last, respectively. The number of elements within each mesh is shown in Table 5. The element type used in all analyses presented within this paper are 8-noded linear bricks.
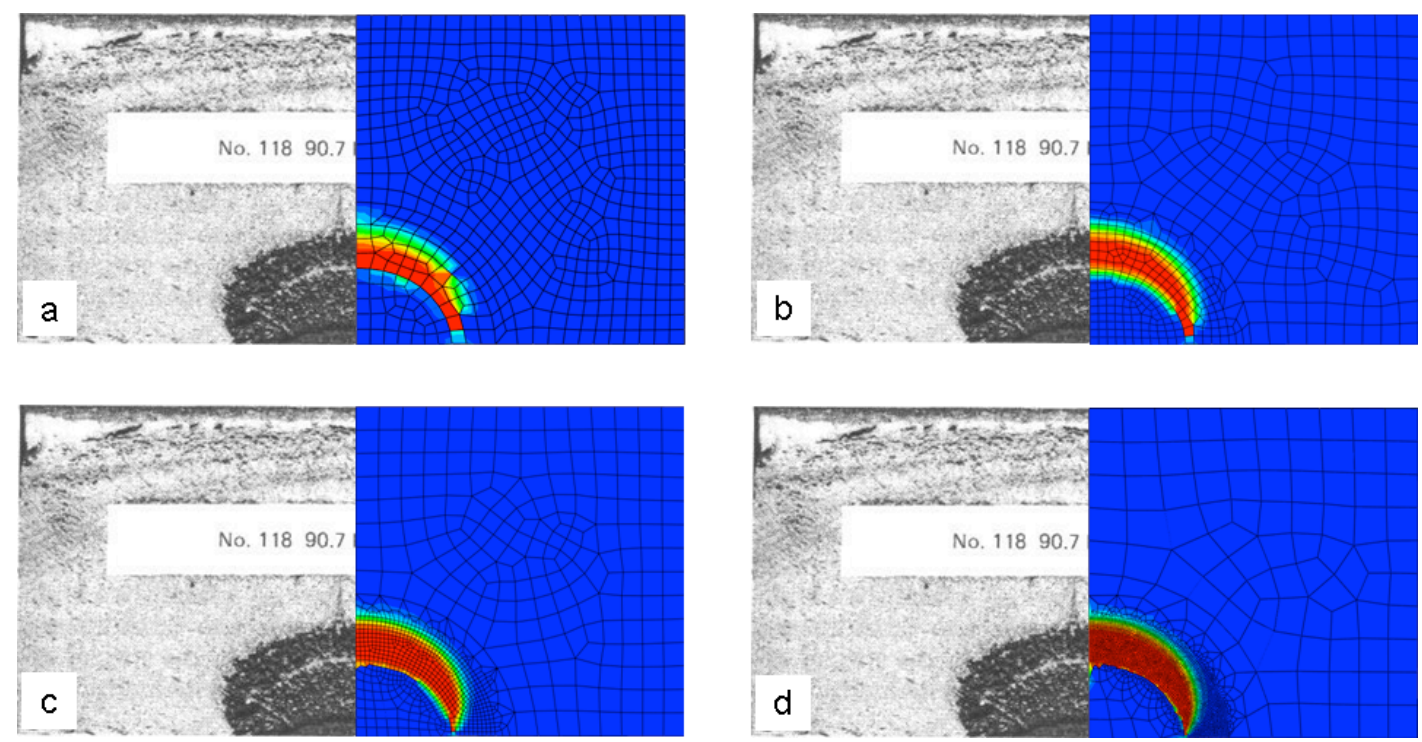

Figure 16. Tested specimen photo to FE damage contour comparisons, showing the mesh sensitivity of the model predictions. (a) Mesh 1 (b) Mesh 2 (c) Mesh 3 (d) Mesh 4.

Table 5. No of nodes/elements in each mesh shown in Figure 16.

\begin{tabular}{|c|c|c|}
\hline Mesh no. & No. of nodes & No. of elements \\
\hline 1 & 5995 & 5010 \\
\hline 2 & 6853 & 5780 \\
\hline 3 & 10109 & 8750 \\
\hline 4 & 26532 & 23700 \\
\hline
\end{tabular}

Figure 17 shows how the crack length at the axis between the experimental photograph and the FE contour in Figure 16 varies with element size. 


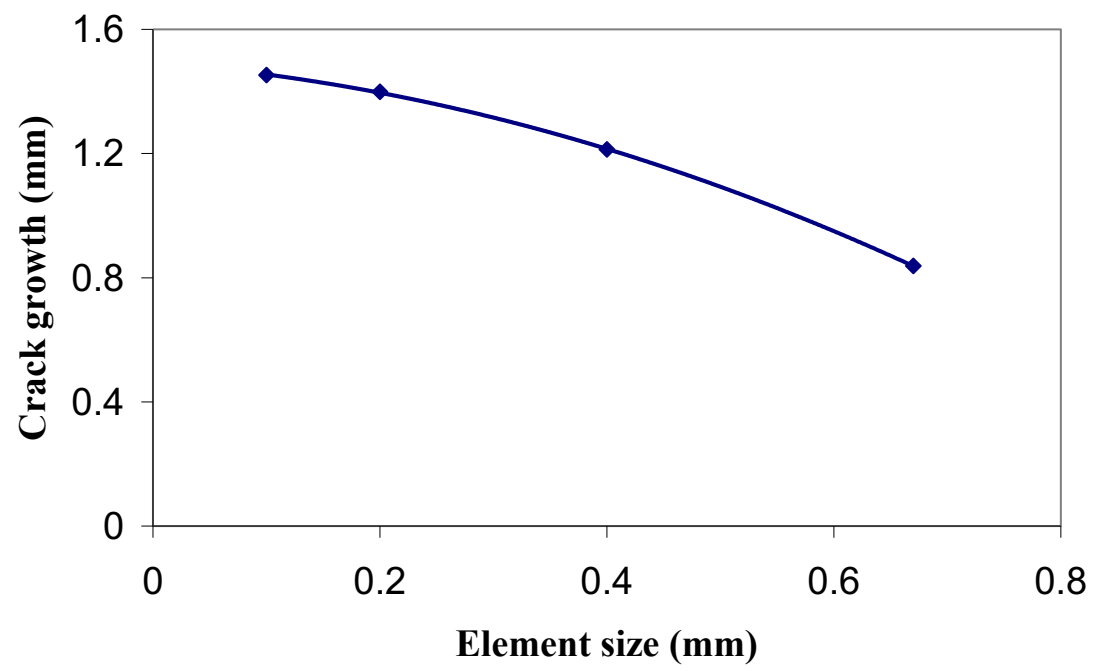

Figure 17. Crack growth vs. element size for thumbnail crack growth predictions (showing mesh sensitivity).

It can be seen from Figure 16 and Figure 17 that as the mesh becomes finer, the predicted solution converges towards the correct solution. The difference between the predictions from the two finest meshes is $3.7 \%$. Due to this small difference, the solution can be considered to have converged. Also, due to the small \% difference, in order to balance the accuracy of solution and time of calculation, a mesh using an element size of $0.2 \mathrm{~mm}$ (mesh (c)) was chosen.

\section{Discussion and future work}

A comprehensive procedure for the determination of the material constants for the Lui \& Murakami creep damage model, based on experimental data has been described and implemented for 316 stainless steel at $600^{\circ} \mathrm{C}$. These constants have been applied to a user subroutine for the Lui \& Murakami model which has been used in conjunction with Finite Element package ABAQUS, in order to provide theoretical predictions for creep crack growth in both compact tension specimen and thumbnail specimen geometries.

Comparisons of the model predictions to corresponding experimental data show extremely encouraging results with the crack fronts matching very closely for both compact tension and thumbnail crack geometries.

Further work includes similar experimentation and material modelling but for materials specifically used in high temperature regions of aeroengines.

\section{Acknowledgements}

The authors would like to thank the EPSRC for the funding of this project obtained from the Doctoral Training Programme. Thanks are also given to Dennis Cooper for his skilful technical support within the experimentation. 


\section{References}

1. Lui, Y. and Murakami, S., "Damage Localization of Conventional Creep Damage Models and Proposition of a New Model for Creep Damage Analysis", JSME International Journal 41 (1998), 57-65.

2. Penny, R. K. and Marriott, D. L., "Design for Creep, McGraw-Hill, Liverpool, 1971.

3. Hyde, T. H., Sun, W. and Becker, A. A., "Creep crack growth in welds: A damage mechanics approach to predicting initiation and growth of circumferential cracks in $\mathrm{CrMoV}$ weldments", Int. J. Pres. Ves. \& Piping 78 (2001), 765-771.

4. Dogan, B. and Ptrovski, B., "Creep crack growth of high temperature weldment." International Journal of Pressure Vessel and Piping 78 (2001), 795-805.

5. Kachanov, L. M., "The time to failure under creep condition", Izv. Akad. Nauk., SSSR. Tekh. Nauk 8 (1958), 26-31.

6. Robotnov, Y. N., "Creep Problems of Structural Members, North-Holland, 1969.

7. Hyde, T. H., "Creep crack growth in 316 stainless steel at $600^{\circ} \mathrm{C}$ ", High Temperature Technology 6 (1988), no. 2, 51-61.

8. R., H. D., R., D. P. and Morrison C. J., "Development of continuum damage in the creep rupture of notched bars", Phil. Trans. R. Soc. Lond. (A) 311 (1984), 103-129.

9. Webster, G. A., Holdsworth, S. R., Loveday, M. S., Perrin, I. J., Nikbin, K., Purper, H., Skelton, R. P. and Spindler, M. W., "A code of practice for conducting notched bar creep rupture tests and for interpreting the data", J. Fatigue and Fatigue of Eng. Materials and Struct. 24 (2004), 319-342.

10. Hyde, T. H. and Sun, W., "Determining high temperature properties of weld materials", JSME International Journal of Solid Mechanics \& Material Engineering, Series A 43 (2000), no. $4,408-414$.

11. Hayhurst, D. R., "Creep rupture under multi-axial states of stress", J. Mech. Phys. Solids. 20 (1972), 381-390. 


\section{Appendix 1}

\section{Kachanov creep damage model}

The multiaxial form of the model first proposed by Kachanov and Robotnov, which has since become known as the Kachanov creep damage law is as follows:

$$
\dot{\varepsilon}_{e q}^{c}=\frac{3}{2} A\left(\frac{\sigma_{e q}}{1-\omega}\right)^{n} t^{m}\left(\frac{S_{i j}}{\sigma_{e q}}\right)
$$

Where $A, n$ and $m$ are material constants.

Considering the uniaxial condition in the 11-direction, equation (7) and equation (9) can be substituted into equation (A1.1) to give the uniaxial form of the model as:

$$
\dot{\varepsilon}_{\text {eq }}^{c}=A\left(\frac{\sigma}{1-\omega}\right)^{n} t^{m}
$$

\section{Determination of the material constants}

If $m$ is considered to be zero, primary creep is neglected and equation (A1.2) can be simplified to the following:

$$
\begin{gathered}
\dot{\varepsilon}^{c}=A\left(\frac{\sigma}{1-\omega}\right)^{n} \\
\dot{\omega}=B \frac{\sigma_{r}{ }^{\alpha}}{(1-\omega)^{\phi}}
\end{gathered}
$$

Where $B, \chi$ and $\varphi$ are material constants and $\sigma_{r}$ is the rupture stress given as shown by equation (6). As for the Lui and Murakami creep damage model, for the uniaxial condition, it is not necessary to determine the material constant, $\alpha$.

\section{A and $n$}

During the initial stages of creep of a material, $\omega \approx 0$ and hence $1-\omega \approx 1$, therefore equation (A1.3) can be simplified to the following:

$$
\dot{\varepsilon}^{c}=A \sigma^{n}
$$

This equation can be seen to be analogous to equation (12), therefore the process used to determine $\mathrm{C}$ and $\mathrm{n}_{2}$ for the Liu and Murakami model can be used to determine A and $\mathrm{n}$ for the Kachanov model, i.e.,

$$
\begin{aligned}
& A=C \\
& n=n_{2}
\end{aligned}
$$

\section{$B, \chi$ and $\varphi$}

For a uniaxial stress state, equation (A1.4) can be written as: 


$$
\frac{d \omega}{d t}=B \frac{\sigma^{\chi}}{(1-\omega)^{\phi}}
$$

Hence, separating the variables and integrating between the limits of 0 and 1 for $\omega$ and 0 and failure time, $t_{f}$, for $t$ gives:

$$
\int_{0}^{1}(1-\omega)^{\phi} d \omega=\int_{0}^{t_{f}} B \sigma^{\chi} d t
$$

As $B \sigma^{\chi}$ is a constant, this equation can be simplified to the following:

$$
\int_{0}^{1}(1-\omega)^{\phi} d \omega=B \sigma^{\chi} \int_{0}^{t_{f}} d t
$$

This equation can be solved and re-arranged for $t_{f}$ to give:

where

$$
t_{f}=\frac{\sigma^{-\chi}}{M}
$$

Equation (A1.7) can be seen to be analogous to equation (21), therefore the process used to determine $\mathrm{D}$ and $\mathrm{p}$ for the Liu and Murakami model can be used to determine $\mathrm{M}$ and $\chi$ for the Kachanov model, i.e.,

$$
\begin{gathered}
M=D \\
p=\chi
\end{gathered}
$$

At this stage, all of the constants for the Kachanov damage model are known except for the $B$ and $\varphi$ values, which are interrelated. The actual values of $B$ and $\varphi$ are found by plotting creep strain curves ( $\varepsilon^{c}$ vs. $t$ ) using the model and varying either $B$ or $\varphi$ (if $B$ changes, so does $\varphi$, and vice versa, as indicated by equation (A1.8)) in order to achieve the best fit to the experimental creep data. This process is very similar to the process described in section 3.2.1 in order to determine $\mathrm{q}_{2}$ for the Liu and Murakami model.

In order to plot $\varepsilon^{c}$ vs. $t$ using the model, $\varepsilon^{c}$ must first be found as a function of $t$. As equation (A1.3) shows, $\dot{\varepsilon}^{c}$ is also a function of $\omega$, which is, in turn, a function of $t$, as shown by equation (A1.4). Therefore, this function for $\omega$ in terms of $t$, must first be found.

By separating the variables in equation (A1.6) and integrating, between the limits of 0 and $\omega$, for $\omega$, and 0 and $t$, for $t$, in order to get a general expression for $\omega$ as a function of $t$ gives:

$$
\int_{0}^{\omega}(1-\omega)^{\phi} d \omega=\int_{0}^{t} B \sigma^{\chi} d t
$$

This equation can be solved to give:

$$
1-\omega=\left(1-B(\phi+1) \sigma^{\chi} t\right)^{1 / \phi+1}
$$

Substituting equation (A1.8) into this equation gives: 


$$
1-\omega=\left(1-M \sigma^{\chi} t\right)^{1 / \phi+1}
$$

Rearranging equation (A1.7) for $M$ gives:

$$
M=\frac{1}{t_{f} \sigma_{r}^{x}}
$$

Substituting this into equation (A1.9) gives:

$$
\begin{aligned}
& 1-\omega=\left(1-\frac{t}{t_{f}}\right)^{1 / \phi+1} \\
& \omega=1-\left(1-\frac{t}{t_{f}}\right)^{1 / \phi+1}
\end{aligned}
$$

This is the expression for $\omega$ as a function of $t$ which is needed.

Therefore, in order to get $\varepsilon^{c}$ as a function of time, equation (A1.10) is substituted into equation (A1.3) to give:

$$
\dot{\varepsilon}^{c}=\frac{d \varepsilon^{c}}{d t}=A\left(\frac{\sigma}{\left(1-\frac{t}{t_{f}}\right)^{1 / \phi+1}}\right)^{n}
$$

By separating the variables and integrating between the limits of 0 and $\varepsilon^{c}$ for $\varepsilon^{c}$ and between the limits of 0 and $t$ for $t$ in order to obtain a general expression for $\varepsilon^{c}$ as a function of $t$ gives:

$$
\int_{0}^{\varepsilon^{c}} d \varepsilon^{c}=A \sigma^{n} \int_{0}^{t} \frac{1}{\left(1-\frac{t}{t_{f}}\right)^{n / \phi+1}} d t
$$

This equation can be solved to give:

$$
\varepsilon^{c}=\frac{A \sigma^{n} t_{f}}{1-\frac{n}{\phi+1}}\left(1-\left(1-\frac{t}{t_{f}}\right)^{1-\frac{n}{\phi+1}}\right)
$$

Although $B$ and $\chi$ do not appear in equation (A1.12) they do appear in the expression for $t_{f}$ (equation (A1.7)) which must be determined before $\varepsilon_{e q}^{c}$ is calculated. Therefore, equation (A1.12) can be used to plot $\varepsilon^{c}$ vs. $t$ for each $\sigma$ value and the value of $\varphi$ is varied (causing $B$ to also vary according to equation (A1.8)) until the general fit of each of the curves (for each stress value) to the experimental data is optimum. An example of this plot using uniaxial creep data for 316 stainless steel, at $600^{\circ} \mathrm{C}$, is shown in Figure A1.1. 


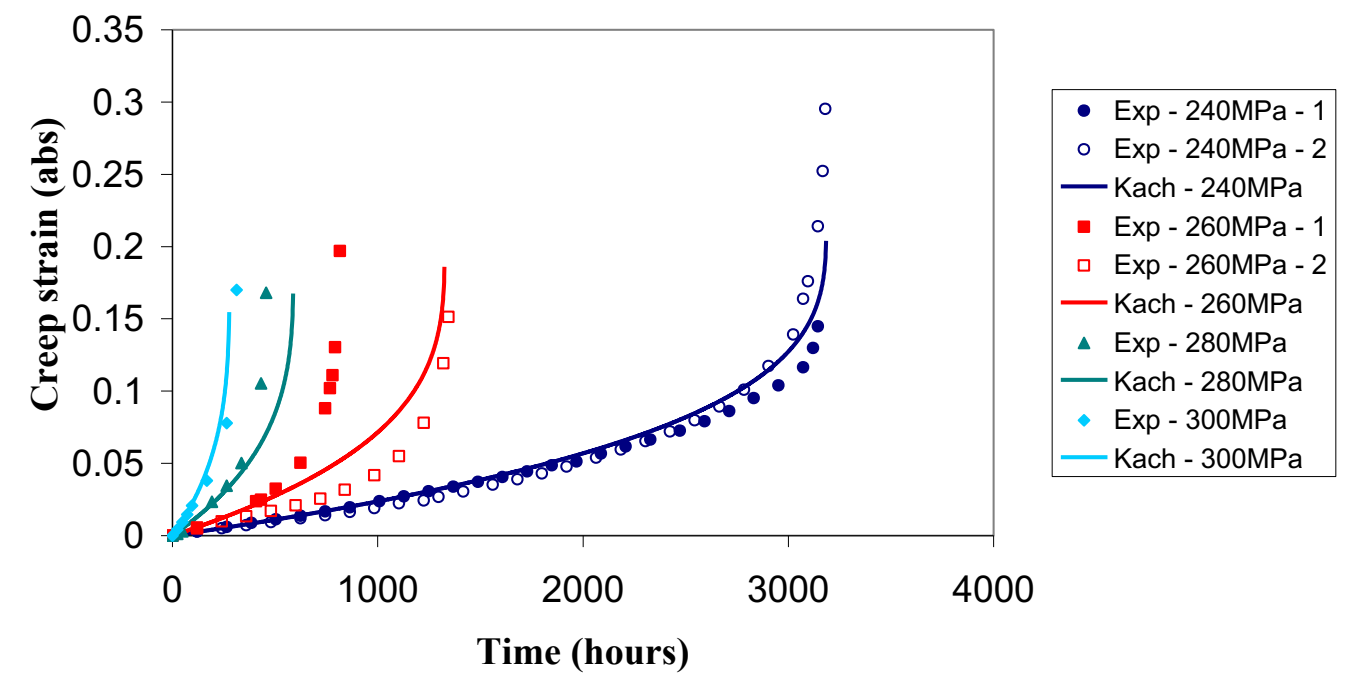

Figure A1.1. Comparison of the Kachanov creep damage model to uniaxial, experimental creep data for 316 stainless steel.

\section{Appendix 2}

\section{Prediction of $\alpha$ from CT FE calculations}

Once equation (29) has been established, i.e.

$$
t_{f}=\frac{1}{D\left(\alpha \sigma_{1}+(1-\alpha) \sigma_{e q}\right)^{p}}
$$

the following process can be used in order to obtain an optimum value for $\alpha$.

Taking logs of both sides of equation (29) gives:

$$
\log \left(t_{f}\right)=\log \left(\frac{1}{D}\right)-p \log \left(\alpha \sigma_{1}+(1-\alpha) \sigma_{e q}\right)
$$

Equation (A2.1) shows a relationship between the constant $\alpha$ and $\log \left(t_{f}\right)$. Therefore, running multiple FE analyses, for a given test component geometry (in this case a CT specimen) using various $\alpha$-values within the range of 0 to 1 allows a plot of $\alpha$ versus $\log \left(t_{f}\right)$ to be produced. As the test data used here is crack growth data (not failure data), the $t_{f}$ value used is strictly the time taken to reach a certain crack length rather than the 'failure time' of the specimen. Traditionally a straight line fitting is applied to this data, the equation of which can be used to obtain the material $\alpha$ value by substitution of the experimental $t_{f}$ value. However, it has been found within this work that for a data set obtained for a CT specimen, a logarithmic curve provides a more accurate fit to the data. An example of this plot for a 316 stainless steel CT specimen geometry (for specimen 3 in Figure 4, i.e. 
using a load of $7.48 \mathrm{kN}$ ), at $600^{\circ} \mathrm{C}$, is shown by Figure A2.1. The application of the experimental $t_{f}$ value and reading of the material $\alpha$-value is indicated by the dashed line.

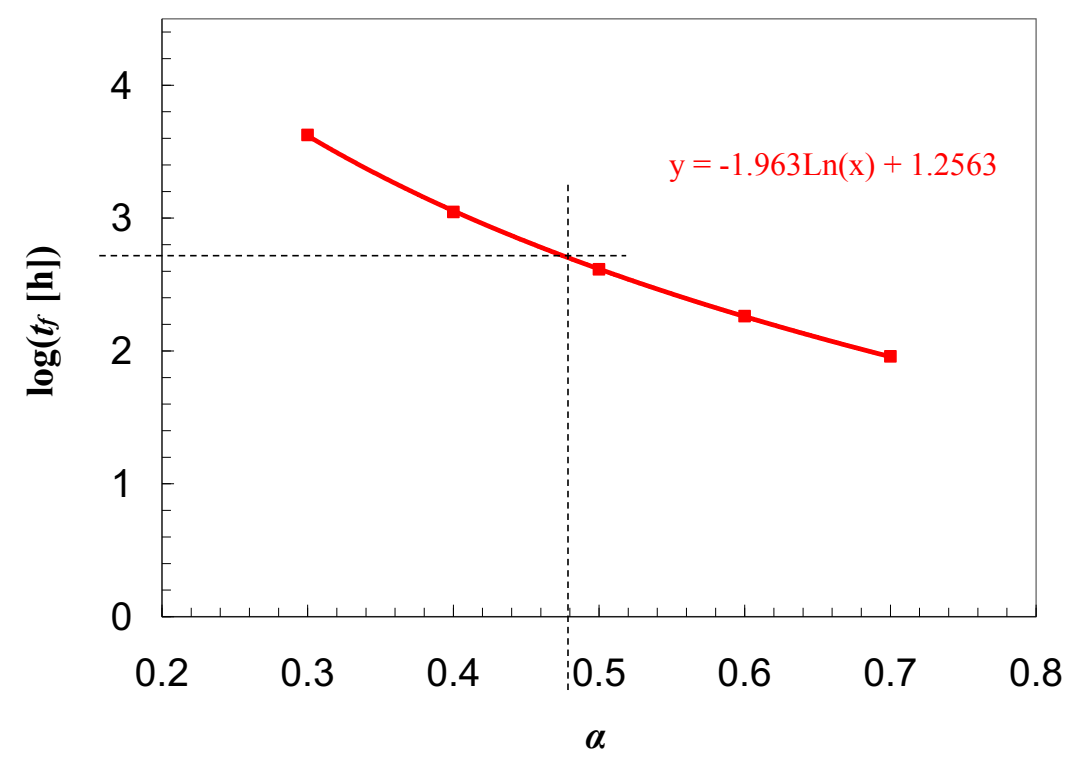

Figure A2.1. Typical $\alpha$ determination graph for 316 stainless steel from CT test data, using a logarithmic fitting.

In order to improve the accuracy of the determined $\alpha$-value, this procedure can be carried out for multiple constant load conditions and the average $\alpha$-value calculated. Based on the three experiments shown by Figure 4, the value of $\alpha$ for 316 stainless steel is calculated as 0.48 . This value for $\alpha$ has been used in all the predictions presented in section 3.2.2 and section 4. 